\title{
Intraoperative, Postoperative and Long-Term Complications of VATS Treatment of Pneumothorax and Bullous Disease. A Review
}

\author{
Luciano Solaini*, Francesco Prusciano, Leonardo Solaini and Massimiliano Carletti
}

\author{
Thoracic Surgery Unit, Department of Surgery, S. Maria delle Croci Hospital Ravenna, Department of Cardio-Thoracic \\ Surgery - Villa Maria Cecilia Hospital Cotignola, Italy
}

\begin{abstract}
Introduction: Video-assisted thoracic surgery (VATS) is considered to be the standard approach in the treatment of pneumothorax and bulluous disease, even if its impact on intraoperative and postoperative morbidity and long-term complications has not been totally evaluated yet. Analysing the author's experience and the literature about this topic, this report aims to ascertain rational criteria to improve the outcomes through the knowledge of all the complications.

Materials and Methodology: At Thoracic Surgery Unit of S. Maria delle Croci Hospital of Ravenna (Italy) were performed 300 VATS procedures for pneumothorax or bulluous disease on 282 patients. All the patients were proposed for the resection of blebs or bullae. At the beginning pleurodesis was achieved by apical pleurectomy and then by talc poudrage.

Results: A pulmonary resection was performed on 289 cases. Apical pleurectomy was carried out in 97 cases, subtotal pleurectomy in 15 cases and talc poudrage in the remaining 198. 33 intraoperative complications occurred with a conversion rate of $2.0 \%$. Postoperative morbidity was $7.0 \%$ including four cases in which re-operation was carried out.

Long-term complications included one Horner's Syndrome and four severe intercostal neuritis. 178 patients were followed up for a mean period of 84 months and the recurrence was observed in six patients.

Conclusions: VATS is a very reliable approach in the treatment of pneumothorax and bulluos disease. To further reduce intraoperative and postoperative morbidity it is necessary to perform the procedure with meticulous caution and to give special attention to secondary pneumothorax and to all cases of adhesions.
\end{abstract}

Keywords: Video-assisted thoracic surgery, pneumothorax, bulluos disease, intraoperative complications, postoperative complications, long-term results, bullectomy, blebectomy, pleurodesis, talc poudrage, pleurectomy.

\section{INTRODUCTION}

The use of thoracoscopy or VATS (Video-Assisted Thoracic Surgery) in the surgical approach of pneumothorax and bullous disease began in the early nineties [1-4] and nowadays is considered to be the standard treatment [5-8]. The procedure consists in resecting the emphysematous parenchyma and in achieving the adhesions between the lung and the chest wall. In order to resect bullae and blebs and to perform pleurodesis different techniques have been proposed, but none of them could be defined as being free of morbidity. The aim of this paper, based on our 16 years experience and on literature review, is to assess intraoperative complications and outcomes in the early postoperative course and in the long term follow up.

\section{MATERIALS AND METHODOLOGY}

From December 1991 to May 2008 at Thoracic Surgery Unit of S. Maria delle Croci Hospital of Ravenna (Italy) 300 VATS procedures for pneumothorax or bullous disease on 282 patients (198 males and 84 females), with mean age of 41 years (range: 14 to 83 years), were performed. The indications

*Address correspondence to this author at the Thoracic Surgery Unit, Villa Maria Cecilia Hospital, Via Corriera 1 Cotignola, RA, Italy; Tel: +39 0545 217586; Fax: +39 0545 217174; E-mail: 1solaini@libero.it for surgery were: primary spontaneous pneumothorax 255, secondary pneumothorax 38 , large bullae 7.18 patients needed a second procedure: in 13 cases due to contralateral pneumothorax and in 5 because of a recurrence on the same side.

The thoracoscopic approach used, as it has been reported elsewhere $[3,9,10]$, was based on three ports accesses. If blebs or bullae were found, they were removed by firing with the 30 $\mathrm{mm}$ stapling device. In case of undetectable bullous disease, the apex of the lung was resected. Large bullae were deflated, twisted and resected.

Up until April 1996 pleurodesis was achieved with apical pleurectomy and afterwards this procedure has been replaced by talc poudrage. In secondary pneumothorax with emphysematous lung and in recurrent pneumothorax, parietal pleurectomy was preferred and parenchymal resections were limited. At the end of the procedure one chest tube was positioned and maintained in aspiration $(-20 \mathrm{~mm} \mathrm{H} 2 \mathrm{O})$ until the second postoperative day. It was removed when no air leak was observed and the patient was discharged the following day after a chest x-ray. Patients were clinically followed up once a year.

\section{RESULTS}

VATS was the starting approach in all cases. The site of air leak was detected only in 12 patients. A resection of the 
lung was performed in 289 cases. Apical pleurectomy was carried out in 97 patients, subtotal pleurectomy in 15 and talc poudrage in the remaining 198 .

In 267 cases (89\%) no complications were reported during the procedure, while in 33 cases intraoperative complications occurred. The greatest difficulty observed was the mobilisation of the lung when the emphysematous tissue or the bullae were adherent to the parietal pleura. In one of these cases the left subclavian artery was accidentally injured leading to sudden bleeding: an emergency thoracotomy with blood transfusion was performed. In 15 cases the particular location of bullae or small parenchymal lacerations required unplanned additional resections and in three patients a conversion to open surgery was needed in order to achieve a satisfactory suture.

In two patients a conversion to thoracotomy was performed to resect sessile giant bullae, because endostaplers were unable to remove them safely. Moreover in 15 patients a fourth port was added in order to accomplish a satisfying control of the operating field or to obtain the right direction of the endostapler for the resection. The majority of these intraoperative complications occurred at the beginning of our centre's VATS experience.

The postoperative course was uneventful in 279 cases (93.0\%) including patients who underwent thoracotomy. Mean hospital stay was $4.5+/-5.3$ days. In 21 cases complications occurred. Two patients were re-operated on by VATS due to bleeding: the first was a consequence of a parietal pleurectomy and the second one due to a damaged muscular vessel in a port site. Two patients with secondary pneumothorax needed prolonged endotracheal intubation for respiratory assistance for 5-8 days after surgery. Three patients had pneumonia, which was successfully treated with antibiotics and physiotherapy. In 12 patients prolonged air leak for more than 5 days was detected. Two of them underwent re-operation, because the lung was not completely re-expanded after 12-14 days. These two cases were surgically treated with further parenchymal sutures one by VATS and the second one by thoracotomy. One of these twelve patients was discharged on the $10^{\text {th }}$ postoperative day with a Heimlich valve, which was removed 15 days later. One patient developed chest wall hematoma, where a port had been inserted. One patient developed intermittent unknown fever, observed for 7 days.

Delayed postoperative complications involved the peripheral nervous system: one case of Horner's syndrome which spontaneously disappeared one month after surgery and four cases of severe intercostal neuritis which had been treated for three to five months with non-steroidal antiinflammatory drugs.

Only 178 (60.3\%) patients underwent long-term follow up. With a mean period of follow up of 84 months (range 3180 months), recurrence of pneumothorax was observed in 6 cases $(3.4 \%)$ and 3 of them (1.7\%) required re-operation.. The recurrence occurred in 5 cases between 12 to 60 months; only one patient had a complete collapse of the lung 15 years after the first treatment. Three patients were simply observed because the pneumothorax was minimal; one of these cases had a second recurrence, but an invasive treatment was not required. In three cases in which re-operation was carried out, residual blebs were not found: one patient underwent talc poudrage and two of them underwent apical pleurectomy during the first procedure. These techniques were not effective for pleurodesis: in two cases the lung was adherent to the pleura only in the apex and in one patient a completely collapsed lung was observed.

\section{DISCUSSION}

VATS is the gold standard surgical approach for pneumothorax and bullous disease. To resect blebs or bullae and to achieve pleurodesis several techniques have been described. The majority of the surgeons prefers endoscopic staplers to remove bullous parenchyma, but also endoscopic suturing $[11,12]$, endoloop ligation $[2,11-14]$ and cautery [15-18] have been employed. Talc poudrage [19-21], pleural abrasion [15, 22-25], pleural argon beam coagulation [26] and partial pleurectomy $[18,27-31]$ are commonly performed to achieve pleurodesis. In order to achieve an efficient adhesion between the pleuras, Chen et al. [32] suggest a mechanical pleurodesis by scrubbing the parietal pleura followed by the instillation of minocycline through the chest tube; Marcheix et al. [33] report a remarkable result with silver nitrate.

The conversion rate to open surgery and postoperative complication rate of the main experiences in literature are showed in Table 1. Margolis et al. [19] report $0 \%$ of intraoperative and postoperative complications: these are the best results reported in literature but in this study the authors enrolled only young adults (median age 19 years old) with spontaneous pneumothorax. Higher complication rates are reported in the other cited papers and they could be explained by the fact that in their studies authors include cases of secondary pneumothorax, which are known as very difficult to manage [30, 34]. In our experience a conversion rate to thoracotomy of $2.0 \%$, mainly due to the treatment of secondary pneumothorax, has been observed. Passlick et al. [16], considering only patients with secondary pneumothorax, report a conversion rate to lateral thorachotomy of $29.4 \%$. Moreover, several authors note that conversion rate dramatically decreases with the improvement of the experience in VATS procedures $[18,30]$.

The most serious intraoperative complication described in the present series and confirmed by data in literature [18, $21,24]$ is bleeding. In several cases it requires immediate thoracotomy. Bleedings usually are due to injuries of systemic vessels during the lysis of the pleural adhesions and therefore it is necessary to proceed carefully during this step. When a major vascular injury occurs, the surgeon must quickly compress the vessel and perform a thoracotomy. If the laceration is small or the bleeding is limited, it could be thoracoscopically managed by applying clips.

As it is reported in our series, a difficult adhesiolysis is the main cause of conversion to thorachotomy $[16,25]$. When the adhesions are extensive or very thick, proceeding by VATS is very tough and therefore open surgery is more expedient. Few authors $[14,35]$ report an initial thoracosopic approach to treat sessile large bullae, but they are usually obliged to convert it for a complete resection. There are no significant correlations between the type of pleurodesis performed and the conversion rate to thoracotomy: talc poudrage, abrasion or partial pleurectomy do not affect a 
Table 1.

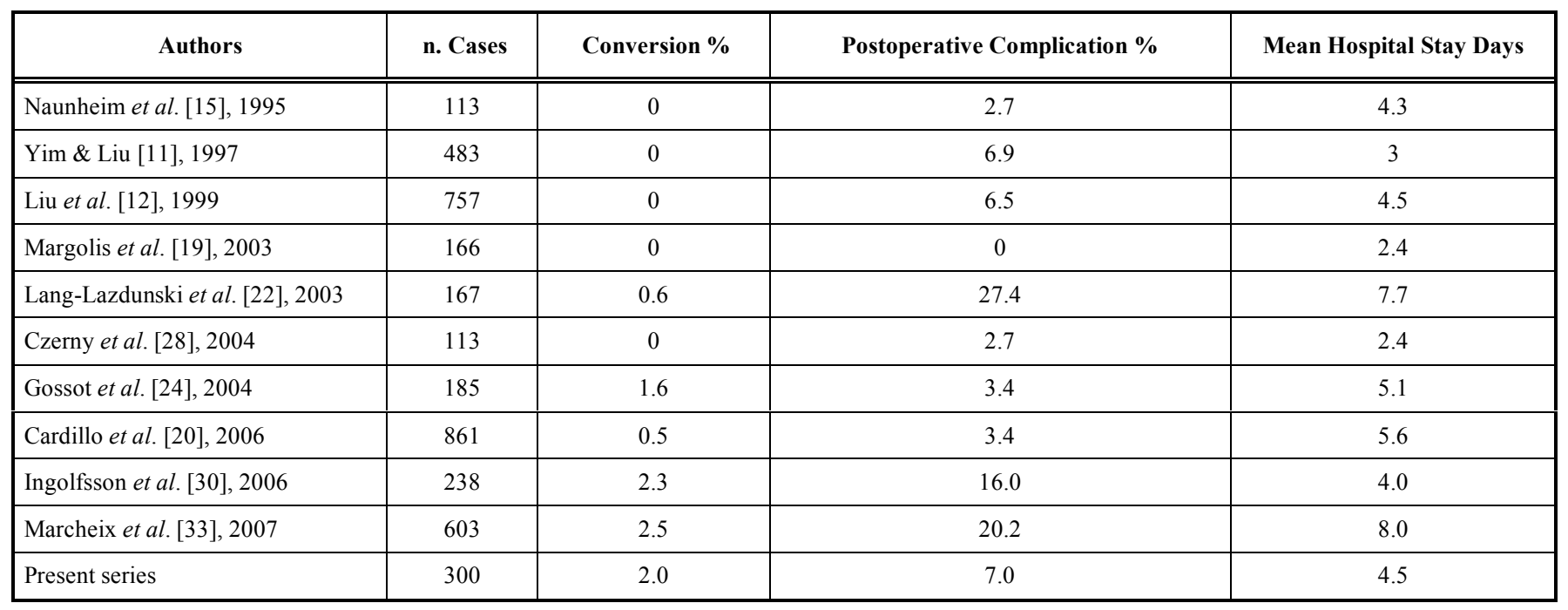

potential intraoperative change of approach. In the end, as it has been recently reported [10], the introduction of thoracoports and technical problems of the video-systems could be also relevant causes of the conversion to open surgery.

During the procedure some adverse events could be managed without opening the chest: 1) lacerations of the parenchyma can be repaired by the endostapler, 2) the excision of large bullae can be performed using the endostapler from different added port sites, 3) in large pulmonary resections, where the residual parenchyma cannot replace completely the chest cavity, the division of the pulmonary ligament is recommended.

In the postoperative course there are some sporadic cases of death $[14,17,34]$ : they were not consequences of VATS technique, but they were directly correlated to the poor preoperative conditions of the patients. The mean hospital stay ranges between 2.4-7.7 days and the morbidity rate ranges from 0 to $27.4 \%$ (Table 1 ). Bleeding requiring reoperation have been reported by some authors $[11,12,24$, $28,35]$, but the source of blood loss was undetectable in several cases. In our experience bleeding was due to the parietal pleurectomy and to the injury of muscular vessels caused by the introduction of thoracoports.

Re-operation has also been reported in cases of persistent air leak or early pneumothorax recurrence $[14,15,17,24$, $26,28,30,34,36]$. In secondary pneumothorax the failure of VATS is due to an incomplete suture of the endostapler or a poor pleurodesis. In order to reduce the complication rate we recommend to check the air leak at the end of the procedure and to stop it just before the insertion of the chest tube. It must be underlined that, besides cases of re-operation, all authors report prolonged air leak, which is the most common postoperative complication. Other causes of morbidity, reported in literature and described in the present series, are: pneumonia [13], atelectasis [24], needing of mechanical ventilation $[17,34]$, wound infections [11-13, 24], empyema $[12,13,30]$, pleural effusion [24], ARDS [30] and Horner's syndrome [20].
Long-term results of VATS treatment of pneumothorax and bullous disease have to consider the chronic pain, the recurrences and the consequences on the pulmonary function. The resection of large bullae improves ventilation, while there is no significant amelioration after blebs resections. No studies showing the impact of the different types of pleurodesis on ventilation have been published. Talc poudrage does not seem to influence the ventilation, as it is reported by Gyorik et al. [21] and Cardillo et al. [37], who do not observe an impaired lung function five years after surgery.

Chronic pain and chest wall paresthesia one year after the procedure have been reported in about $21 \%$ of the patients $[22,23,27,38]$, in particular in those who underwent pleurectomy. In order to avoid these complications, Jutley et al. [39] propose the uniportal VATS technique, but the study is limited by the short follow up and by the small number of cases. Chen et al. [40] have suggested the use of needlescopic instruments which, compared with the conventional ones, reduce the residual neuralgia. Probably these methods will spread among surgeons in the next future when the technique will be easier. Postoperative pain is reported in literature [10] as a general complication of VATS. We believe it is not specifically related to the treatment of the pneumothorax. In patients who develop pneumothorax the postoperative pain is more common, probably because subjects are younger and much more sensitive to pain. To evaluate the quality of life after surgical treatment of pneumothorax Ben-Nun et al. [25] compared VATS and limited thoracotomy observing that patients in the thoracotomy group needed significantly higher doses of narcotic analgesia for a longer period than patients in the VATS group. Similarly Balduyck et al. [31] in a recent prospective study have demonstrated that VATS has an improved thoracic pain evolution than antero-lateral thoracotomy. In the same paper they also report a significant difference one month postoperatively between VATS and open surgery in physical, role and cognitive functioning and dyspnoea in favour of VATS.

The recurrence rate after VATS treatment for pneumothorax is very low and it ranges between 0 and $5.8 \%$ 
Table 2.

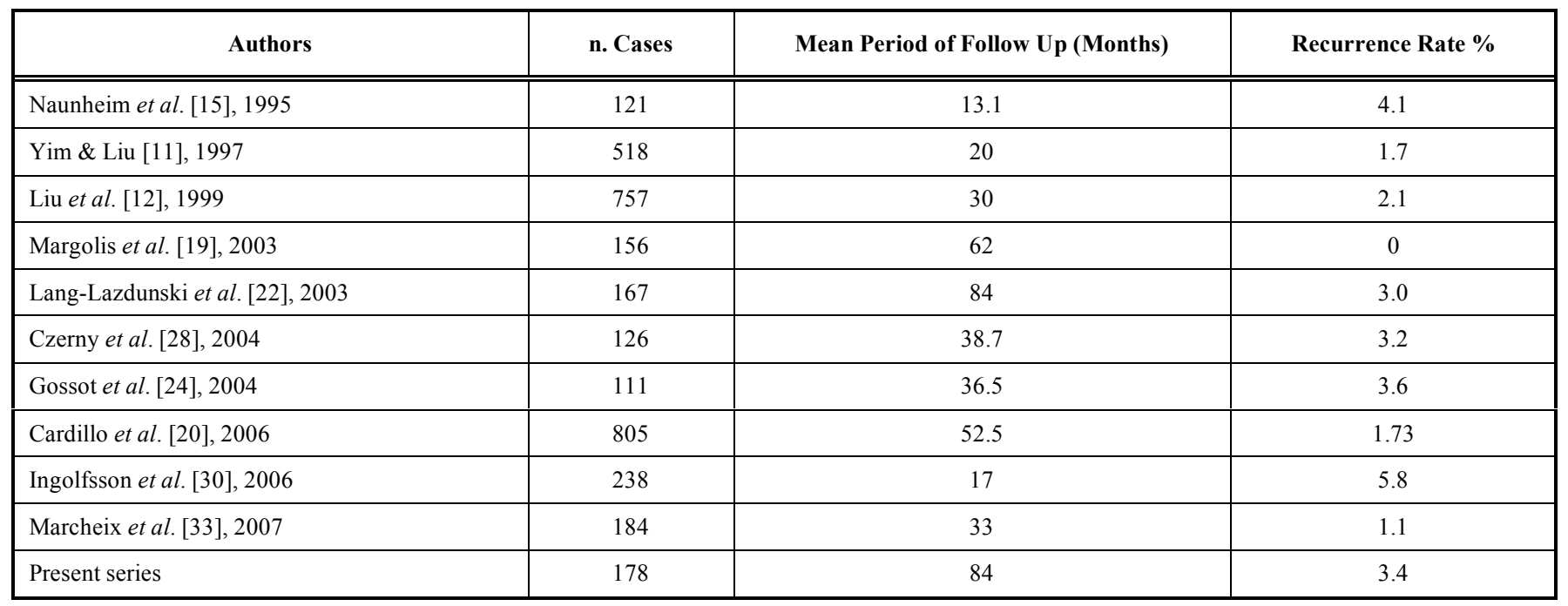

(Table 2). Several studies have a period of follow up less than five years and include primary and secondary pneumothorax as well as different kinds of emphysematous disease. Besides the cases in which there are evidences of missed blebs or bullae, the recurrence seems to depend on the type of pleurodesis performed. Apparently pleural abrasion $[22,24]$ has been associated to slightly worse results than talc poudrage [20], but it is very difficult to compare the different retrospective data published in literature.

In a review about the recurrence rate of pneumothorax in randomised and non-randomised trials, Barker et al. [41] report that the recurrence of pneumothorax, when the same pleurodesis procedure is performed, is four-fold increased after VATS approaches rather than open approaches. Different results were previously published by Sawada et al. [42], who did not observe a statistical difference between videothoracoscopy and thoracotomy. However we believe that these data, slightly in favour of open surgery, do not affect the excellence of VATS in the treatment of pneumothorax.

\section{CONCLUSION}

Surgical treatment of pneumothorax is the most widespread indication for the VATS technique. We observe excellent results in primary pneumothorax, but in the secondary one the morbidity rate is still high. Only if the surgeon performs the procedure with meticulous caution he will be able to decrease the complication rate. A prudent adhesiolysis and a systematic check for air leak and bleeding at the end of the procedure are essential steps to avoid complications.

The recurrence rate after videothoracoscopic treatment is very low and when it occurs it probably depends on the insufficient pleurodesis. Despite the different modalities proposed to perform pleurodesis, a completely safe technique to achieve a lasting adhesion of the two pleuras has not been proposed yet. We emphasize the use of talc poudrage because it is simple to use and it guarantees valuable results without significant complications.

\section{REFERENCES}

[1] Peillon C, Testart J Surgical. Thoracoscopy. Presse Med 1991; 20: 125-1217.

[2] Nathanson LK, Shimi SM, Wood RAB, Cuschieri A Videothoracoscopic ligation of bulla and pleurectomy for spontaneous pneumothorax. Ann Thorac Surg 1991; 52: 316-9.

[3] Solaini L, Perrucci A, Bagioni P, Grandi U, Stancanelli V. Thoracoscopic surgical treatment of spontaneous pneumothorax. Chirurgia 1992; 5: 188-90.

[4] Hazelrigg SR, Nunchuck SK, LoCicero J and the Video Assisted Thoracic Surgery Study Group. Video-assisted thoracic surgery study group data. Ann Thorac Surg 1993; 56: 1039-44.

[5] Baumann MH, Strange C, Heffner JE, et al. AACP Pneumothorax Consensus Group Management of spontaneous pneumothorax. An American College of Chest Physician Delphi Consensus Statement. Chest 2001; 119: 590-602.

[6] Sedrakyan A, van der Meulen J, Lewsey J, Treasure T. Video assisted thoracic suergery for treatment of pneumothorax and lung resections: systematic review of randomised clinical trials. BMJ 2004; 329: 1008-12.

[7] $\mathrm{Ng}$ CSH, Lee TW, Wan S, Yim APC. Video assisted thoracic surgery in the management of spontaneous pneumothorax: the current status. Postgrad Med 2006; 82: 179-85.

[8] Sakurai H. Videothoracoscopic surgical approach for spontaneous pneumothorax: a review of the pertinent literature. World J Emerg Surg 2008; 3: 23-7.

[9] Solaini L, Bagioni P, Grandi U Role of videoendoscopy in pulmonary surgery: Present experience. Eur J Cardiothorac Surg 1995; 9: 65-8.

[10] Solaini L, Prusciano F, Bagioni P, et al. Video-Assisted Thoracic Surgery (VATS) of the lung. Analysis of the intraoperative and postoperative complications in 15 years and review of the literature. Surg Endosc 2008; 22: 298-310.

[11] Yim APC, Liu HP. Video-assisted thoracoscopic management of primary spontaneous pneumothorax. Surg Laparosc Endosc 1997; 7: 236-40.

[12] Liu HP, Yim APC, Izzat BM, Lin PJ, Chang CH. Thoracoscopic surgery for spontaneous pneumothorax. World J Surg 1999; 23: 1133-6.

[13] Liu HP, Chang CH, Lin PJ, Chu JJ, Hsieh MJ. An alternative technique in the management of bullous emphysema thoracoscopic endoloop ligation of bulla. Chest 1997; 111: 489-93.

[14] Menconi GF, Melfi FM, Mussi A, et al. Treatment by VATS of giant bullous emphysema: results. Eur J Cardiothorac Surg 1998; 131: 66-70.

[15] Naunhein KS, Mack MJ, Hazelrigg SR, et al. Safety and efficacy of video-assisted thoracic surgical techniques for the treatment of spontaneous pneumothorax. J Thorac Cardiovasc Surg 1995; 109: 1198-204. 
[16] Passlick B, Born C, Haussinger K, Thetter O. Efficiency of videoassisted thoracic surgery for primary and secondary spontaneous pneumothorax. Ann Thorac Surg 1998; 65: 324-7.

[17] Rieger R, Woisetschlager R, Schrenk P, Wayand W. Thoracoscopic bleb resection selectively combined with pleurectomy for complicated spontaneous pneumothorax. Eur J Surg 1998; 164: 333-8.

[18] Roviaro G, Varoli F, Vergani C, Maciocco M. State of the art in thoracoscopic surgery: a personal experience of 2000 videothoracoscopic procedures and an overview of the literature. Surg Endosc 2002; 16: 881-92.

[19] Margolis M, Gharagozloo F, Tempesta B, et al. Video-assisted thoracic surgical treatment of initial spontaneous pneumothorax in young patients. Ann Thorac Surg 2003; 76: 1661-4.

[20] Cardillo G, Carleo F, Giunti R, et al. Videothoracoscopic talc poudrage in primary spontaneous pneumothorax: a singleinstitution experience in 861 cases. J Thorac Cardiovasc Surg 2006; 131: 322-8.

[21] Gyorik S, Erni S, Studler U, et al. Long-term follow-up of thoracoscopic pleurodesis for primary spontaneous pneumothorax. Eur Respir 2007; J 29: 757-60.

[22] Lang-Lazdunski L, Chapuis O, Bonnet PM, et al. Videothoracoscopic bleb excision and pleural abrasion for the treatment of primary spontaneous pneumothorax. Ann Thorac Surg 2003; 75: 960-5.

[23] Sihoe ADL, Au SSW, Cheung ML, et al. APC Incidence of chest wall paresthesia after video-assisted thoracic surgery for primary spontaneous pneumothorax. Eur J Cardiothorac Surg 2004; 25: 1054-8.

[24] Gossot D, Galetta D, Stern JB, et al. Results of thoracoscopic pleural abrasion for primary spontaneous pneumothorax. Surg Endosc 2004; 18: 466-71.

[25] Ben-Nun A, Soudack M, Best LA. Video-assisted thoracoscopic surgery for recurrent spontaneous pneumothorax : the long term benefit. World J Surg 2006; 30: 285-90.

[26] Bobbio A, Ampollini L, Internullo E, et al. Thoracoscopic parietal pleural argon beam coagulation versus pleural abrasion in the treatment of primary spontaneous pneumothorax. Eur J Cardiothorac Surg 2006; 29: 6-8.

[27] Passlick B, Born C, Sienel W, Thetter O. Incidence of chronic pain after minimal invasive surgery for spontaneous pneumothorax. Eur J Cardiothorac Surg 2001; 19: 335-9.

[28] Czerny M, Salat A, Fleck T, et al. Lung wedge resection improves outcome in stage I primary spontaneous pneumothorax. Ann Thorac Surg 2004; 77: 1802-5.

[29] Ayed AK, Chandrasekaran C, Sukumar M. Video-assisted thoracoscopic surgery for primary spontaneous pneumothorax: clinicopathological correlation. Eur J Cardiothorac Surg 2006; 29: $221-5$.
[30] Ingolfsson I, Gyllstedt E, Lillo-Gil R, et al. Reoperations are common following VATS for spontaneous pneumothorax: study of risk factors. Interact Cardiovasc Thorac Surg 2006; 5: 602-7.

[31] Balduyck B, Hendriks J, Lauwers P, Van Schil P. Quality of life evolution after surgery for primary or secondary spontaneous pneumothorax: a prospective study comparing different surgical techniques. Interact Cardiovasc Thorac Surg 2008; 7: 45-9.

[32] Chen JS, Hsu HH, Kuo SW, et al. Effects of additional minocycline pleurodesis after thoracoscopic procedures for primary spontaneous pneumothorax. Chest 2004; 125: 50-5.

[33] Marcheix B, Brouchet L, Renaud C, et al. Videothoracoscopic silver nitrate pleurodesis for primary spontaneous pneumothorax: an alternative to pleurectomy and pleural abrasion? Eur J Cardiothorac Surg 2007; 31: 1106-9.

[34] Waller DA, Forty J, Soni AK, et al. Videothoracoscopic operation for secondary spontaneous pneumothorax. Ann Thorac Surg 1994; 57: $1612-5$.

[35] Jancovici R, Lang-Lazdunski L, Pons F, et al. Complications of Video-Assisted Thoracic Surgery: a five-year experience. Ann Thorac Surg 1996; 61: 533-7.

[36] Yim APC, Ho JKS. One hundred consecutive cases of videoassisted thoracoscopic surgery for primary spontaneous pneumothorax. Surg Endosc 1995; 9: 332-6.

[37] Cardillo G, Carleo F, Carbone L, et al. Long-term function following videothoracoscopic talc poudrage for primary spontaneoius recurrent pneumothorax. Eur J Cardiothorac Surg 2007; 31: 802-5.

[38] Landreneau RJ, Wiechmann RJ, Hazelrigg SR, et al. Effect of minimally invasive thoracic surgical approaches on acute and chronic postoperative pain. Chest Surg Clin N Am 1998; 8: 891906.

[39] Jutley RS, Khalil MW, Rocco G. Uniportal vs standard three port VATS technique for spontaneous pneumothorax: comparison of post-operative pain and residual paraesthesia. Eur J Cardiothorac Surg 2005; 28: 43-6.

[40] Chen JS, Hsu HH, Kuo SW, et al. Needlescopic versus conventional video-assisted thoracic surgery for primary spontaneous pneumothorax: a comparative study. Ann Thorac Surg 2003; 75: 1080-5.

[41] Barker A, Maratos EC, Edmonds L, Lim E. Recurrence rates of video-assisted thoracoscopic versus open surgery in the prevention of recurrent pneumothoraces: a systematic review of randomised and non-randomised trials. Lancet 2007; 370: 329-35.

[42] Sawada S, Watanabe Y, Moriyama S. Video-assisted thoracoscopic surgery for primary spontaneouspneumothorax: evaluation of indications and long-term outcome compared with conservative treatment and open thoracotomy. Chest 2005; 127: 2226-30. 